\title{
EXPERIMENTS ON THE DENSITY OF TSUNAMI INUNDATION WATER AND ITS INFLUENCE ON THE TSUNAMI RUN-UP AND DEPOSIT
}

\author{
Hideo Matsutomi ${ }^{1}$ and Fumiko Konno ${ }^{2}$
}

\begin{abstract}
For the sophistication of the tsunami load, future and historical tsunami scale evaluations, the dependency of the density of tsunami inundation water with sediment on the hydraulic quantities, and then the dependencies of the tsunami run-up distance, sediment deposit distance, mean sediment deposit thickness on the density of the tsunami inundation water are examined through a devised small-scale hydraulic experiment. Within the experimental range of this study, it is verified that the density of the tsunami inundation water depends on the Froude number of the incident tsunami inundation flow and the sediment grain size, and the relative tsunami run-up distance (= the run-up distance of the inundation water with sediment/the run-up distance of the inundation water without sediment $(=$ fresh water)), ratio of the tsunami sediment deposit distance to the tsunami run-up distance, ratio of the mean tsunami sediment deposit thickness to the tsunami sediment deposit distance depend on the density of the tsunami inundation water, and four empirical expressions for those dependencies are proposed.
\end{abstract}

Keywords: density of inundation water with sediment; run-up; sediment deposit; tsunami; experiment

\section{INTRODUCTION}

The density $\rho$ (or the specific gravity $\rho / \rho_{w}$ where $\rho_{w}$ is the density of the fresh water) of tsunami inundation water with sediment would have influences on the tsunami horizontal and vertical forces (tsunami load) linearly as easily inferred from the expressions such as the hydrostatic pressure and momentum theorem, the thickness and extent of tsunami sediment deposit (Matsutomi et al. 2017), etc.

In the evaluation of the tsunami load even on the land structures including RC buildings (AIJ 2015), the density of tsunami inundation water has been treated as a fixed value of $1.03 \mathrm{~g} / \mathrm{cm}^{3}$ so far. The Federal Emergency Management Agency (FEMA 2012) recommended $1.2 \mathrm{~g} / \mathrm{cm}^{3}$ as the maximum density of the vertical cross section average of tsunami inundation water with sediment assuming that the sediment concentration of the vertical cross section average of the tsunami inundation flow was $10 \%$, without presenting any concrete grounds and references. There is no fixed view on the maximum density of the vertical cross section average of inundation water with sediment even in the case of river flood that is more frequent than tsunami.

In the light of the above circumstances, this study aims to examine the dependency of the density $\rho$ of the tsunami inundation water on hydraulic quantities such as the Froude number $F_{r i}$ of incident tsunami inundation flow, and the dependencies of the tsunami run-up distance $L_{R}$, sediment deposit distance $L_{R S}$, mean sediment deposit thickness $Z$ on the density $\rho$ of the tsunami inundation water through a devised small-scale hydraulic experiment for the sophistication of the tsunami load, future and historical tsunami scale evaluations.

\section{HYDRAULIC EXPERIMENTS}

\section{Soils}

Soils having different grain size distribution are used in the experiments. As shown in Fig. 1,

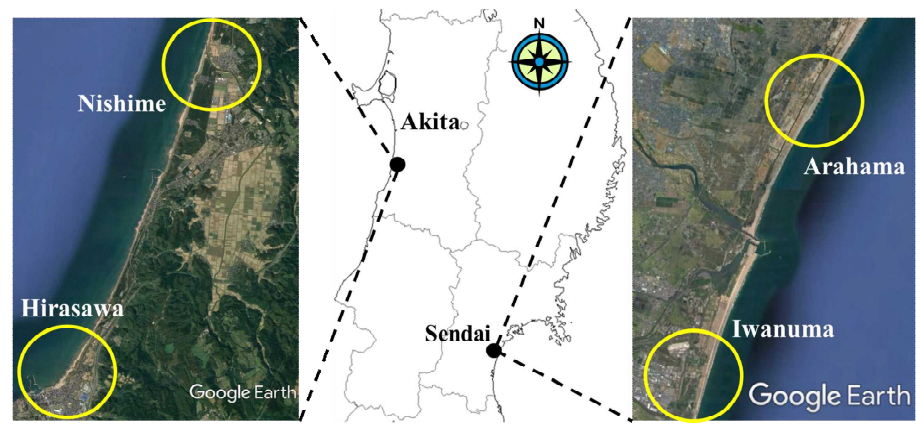

Figure 1. Soil collection sites on the Akita coast (left) and Sendai coast (right) of Tohoku in Japan.

\footnotetext{
${ }^{1}$ Graduate School of Engineering Science, Akita University, 1-1 Tegata Gakuen-machi, Akita, 010-8502, Japan

${ }^{2}$ Urban and regional development Division, Nippon Koei, 1-14-6 Kudan-kita, Chiyoda-ku, Tokyo, 102-8539, Japan
} 
Table 1. Experimental conditions and grain size distribution characteristics of soils.

\begin{tabular}{|c|c|c|c|c|c|c|c|c|c|c|c|c|c|c|c|c|c|}
\hline Case & Site & $\begin{array}{l}h_{D} \\
(\mathrm{~m})\end{array}$ & $\begin{array}{c}h_{U} \\
(\mathrm{~cm})\end{array}$ & $\begin{array}{l}S_{1} \\
\left({ }^{\circ}\right)\end{array}$ & $\begin{array}{c}L_{S} \\
(\mathrm{~m})\end{array}$ & $\begin{array}{c}h_{S} \\
(\mathrm{~cm})\end{array}$ & $\begin{array}{l}S_{2} \\
\left({ }^{\circ}\right)\end{array}$ & $\begin{array}{l}S_{3} \\
\left({ }^{\circ}\right)\end{array}$ & $\begin{array}{l}S_{4} \\
\left({ }^{\circ}\right)\end{array}$ & $\begin{array}{c}L_{G} \\
(\mathrm{~cm})\end{array}$ & $\begin{array}{c}L_{V} \\
(\mathrm{~cm})\end{array}$ & $\begin{array}{c}h_{T} \\
(\mathrm{~cm})\end{array}$ & $\begin{array}{c}M_{S D} \\
(\mathrm{~kg})\end{array}$ & $\begin{array}{l}M_{S R} \\
(\mathrm{~kg})\end{array}$ & $\begin{array}{c}d_{50} \\
(\mathrm{~mm})\end{array}$ & U.C. & C.C. \\
\hline $1-1$ & $S$ & 2.0 & 25 & 35 & 0.85 & 20 & 30 & - & 45 & 5 & 0 & 6 & 25.5 & - & 0.39 & 2.39 & 1.16 \\
\hline $2-1$ & \multirow{8}{*}{$S$} & \multirow{8}{*}{1.2} & \multirow{8}{*}{25} & \multirow{8}{*}{20} & \multirow{8}{*}{1.55} & \multirow{8}{*}{23} & \multirow{8}{*}{12} & \multirow{8}{*}{7.3} & \multirow{8}{*}{45} & \multirow{8}{*}{0} & \multirow{8}{*}{0} & 2 & 15.5 & 15.5 & 0.28 & 2.42 & 1.08 \\
\hline $2-2$ & & & & & & & & & & & & 6 & 42.7 & 41.6 & 0.32 & 2.41 & 1.23 \\
\hline $2-3$ & & & & & & & & & & & & 2 & 11.5 & 10.0 & 0.31 & - & - \\
\hline $2-4$ & & & & & & & & & & & & 6 & 35.3 & 30.2 & 0.31 & - & - \\
\hline $2-5$ & & & & & & & & & & & & 2 & 15.8 & 16.0 & 0.33 & 2.25 & 1.27 \\
\hline $2-6$ & & & & & & & & & & & & 6 & 40.8 & 40.5 & 0.36 & 1.95 & 1.08 \\
\hline $2-7$ & & & & & & & & & & & & 2 & 11.5 & 9.5 & 0.28 & - & - \\
\hline $2-8$ & & & & & & & & & & & & 6 & 39.3 & 39.1 & 0.30 & 2.56 & 1.16 \\
\hline $3-1$ & \multirow{5}{*}{ A } & \multirow{5}{*}{1.0} & \multirow{5}{*}{25} & \multirow{5}{*}{16} & \multirow{5}{*}{1.45} & \multirow{5}{*}{23} & \multirow{5}{*}{12} & \multirow{5}{*}{7.3} & \multirow{5}{*}{$\begin{array}{c}55 \\
\& \\
70\end{array}$} & \multirow{5}{*}{0} & \multirow{5}{*}{0} & 0.5 & 3.0 & 3.0 & 0.21 & 2.17 & 1.13 \\
\hline $3-2$ & & & & & & & & & & & & 1 & 8.0 & 8.0 & 0.21 & 2.17 & 1.13 \\
\hline $3-3$ & & & & & & & & & & & & 2 & 16.0 & 16.0 & 0.21 & 2.17 & 1.13 \\
\hline $3-4$ & & & & & & & & & & & & 6 & 40.0 & 40.0 & 0.21 & 2.17 & 1.13 \\
\hline $3-5$ & & & & & & & & & & & & 6 & 40.0 & 40.0 & 0.24 & 2.08 & 0.92 \\
\hline 4-1 & \multirow{9}{*}{$S$} & \multirow{9}{*}{0.5} & \multirow{6}{*}{25} & \multirow{9}{*}{8} & \multirow{9}{*}{3.01} & \multirow{9}{*}{8} & & & & & & 0.5 & 10.5 & 10.5 & 0.25 & 1.50 & 1.00 \\
\hline $4-2$ & & & & & & & & & & & & 1 & 15.5 & 15.5 & 0.25 & 1.37 & 0.98 \\
\hline $4-3$ & & & & & & & & & & & & 2 & 25.5 & 25.5 & 0.25 & 1.37 & 0.98 \\
\hline $4-4$ & & & & & & & & & & & & 6 & 73.0 & 73.0 & 0.28 & 1.43 & 0.99 \\
\hline $4-5$ & & & & & & & 5 & 3.5 & 90 & -1 & 11.5 & 6 & 73.0 & - & 0.29 & 1.68 & 0.94 \\
\hline $4-6$ & & & & & & & & & & & & 6 & 73.0 & - & 0.22 & 1.29 & 1.02 \\
\hline $4-7$ & & & 20 & & & & & & & & & 6 & - & 73.0 & 0.25 & 1.42 & 0.94 \\
\hline $4-8$ & & & 23 & & & & & & & & & 6 & - & 73.0 & 0.25 & 1.42 & 0.94 \\
\hline $4-9$ & & & 30 & & & & & & & & & 6 & - & 73.0 & 0.24 & 1.44 & 0.94 \\
\hline
\end{tabular}

Where A: Akita coast, S: Sendai coast, U.C.: Uniformity Coefficient, C.C.: Curvature Coefficient.

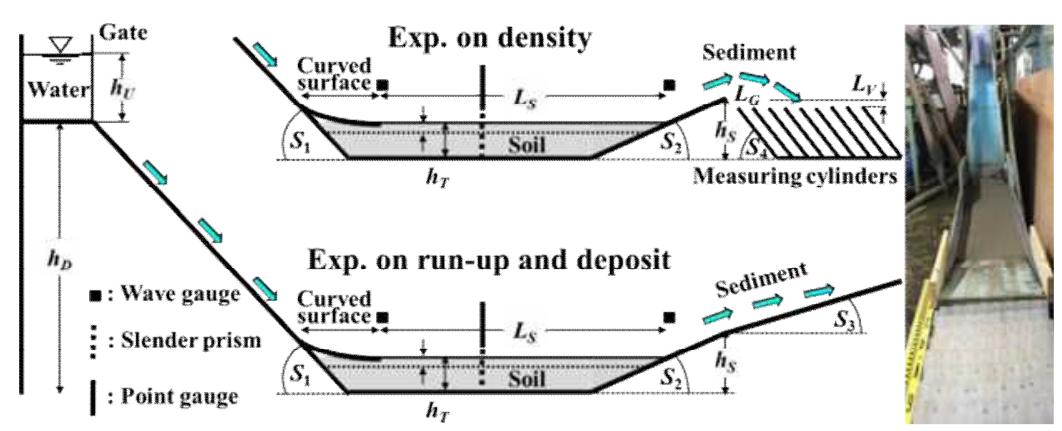

Figure 2. Outline of the experimental flume (sidewalls are omitted), its frontal view (right side), arrangement of measuring instruments and definition of symbols.

the soils were collected on the Akita coast (Nishime, Hirasawa) and on the Sendai coast (Arahama, Iwanuma) inundated by the 2011 Tohoku Tsunami. The grain size distribution characteristics of the collected soils spread in the horizontal flume before carrying out the experiments are shown in Table 1 .

\section{Experimental Method}

Experimental equipment. Experimental flume with $0.3 \mathrm{~m}$ in width is a handmade open channel of slide type, which can easily generate inundation flow with a high Shields number. A horizontal flume to spread the collected soil is attached to the downstream end of the slide slope with the inclination $S_{1}$. A short mild upslope with the inclination $S_{2}$ is installed at the downstream end of the horizontal flume to catch a proper amount of inundation water with sediment with the measuring cylinders inclined at $S_{4}$ on the upstream side. A curved surface part is set up to smoothly connect the slide slope to the horizontal flume. In the experiments on the tsunami run-up and sediment deposit, a long mild upslope with the inclination $S_{3}$, pasted sands of 0.85 to $2.0 \mathrm{~mm}$ in diameter to increase the surface roughness, is attached to the downstream end of the short mild upslope. Outline of the experimental flume, its frontal view (right side), arrangement of the measuring instruments (measuring cylinders, wave gauges, slender prism, point gauge) and 


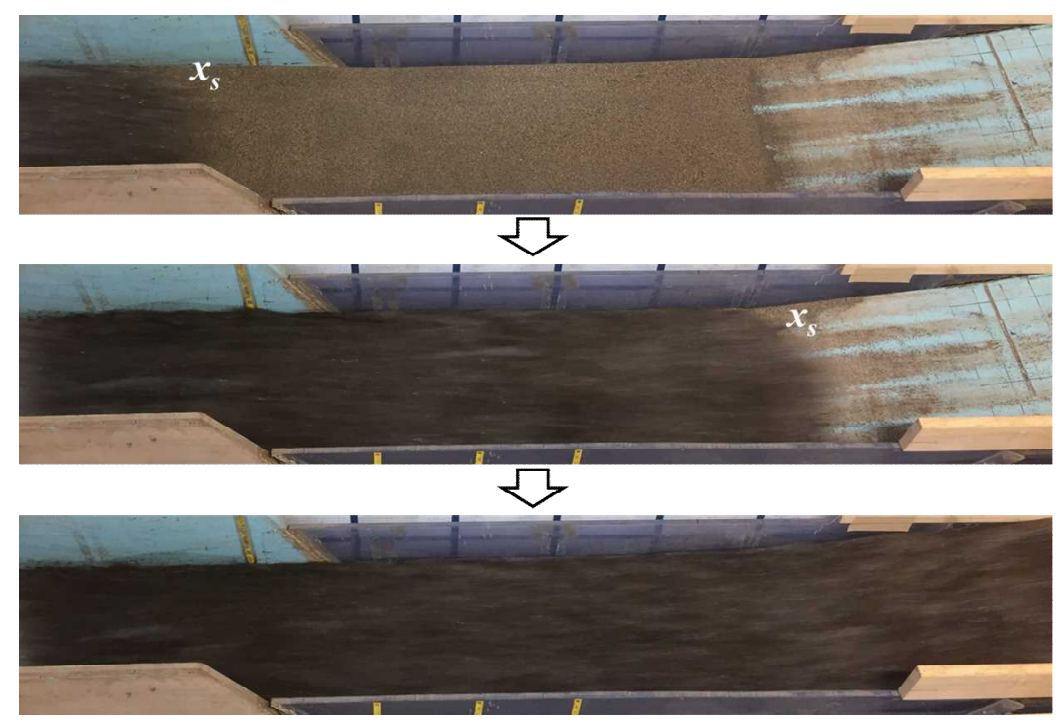

Figure 3. Snapshots (video images) of the inundation flow with a large amount of sediment in the early experiments, where $x_{s}$ is the front position of the inundation flow (Case 1-1: $L_{s}=0.85 \mathrm{~m}, h_{T}=6 \mathrm{~cm}$ ).

definition of symbols are shown in Fig. 2, where side walls of the flume are omitted.

Inundation flows are generated by rapidly pulling up a gate of water tank with $0.3 \mathrm{~m}$ in width and $0.3 \mathrm{~m}$ to $0.45 \mathrm{~m}$ in length, mounted on the top of the slide with the height $h_{D}$ from the ground level.

Adjustment of the density of the inundation water. The density $\rho$ of the inundation water is forcibly adjusted by changing the initial thickness $h_{T}$ of the spread soil layer in the horizontal flume while moving the bottom surface of the horizontal flume up and down, including the case that the bottom surface of the horizontal flume is exposed by the inundation flow.

Measurement of hydraulic quantities. Inundation depths at two points in the horizontal flume and the short mild upslope respectively (see Fig. 2) and moving velocity of a surge front position $x_{s}$ (see Fig. 3) in the horizontal flume are measured by using both ultrasonic wave gauges (KEYENCE, UD-500) and video cameras. The heights of the bottom surface at the two points where the ultrasonic wave gauges are installed are the same each other. The angle of the Mach wave generated by two ways of the tip of a point gauge arranged in the upper part of the central area and a slender prism (length $\times$ width $\times$ height of $2 \mathrm{~mm} \times 4 \mathrm{~mm} \times 200 \mathrm{~mm}$ ) attached to the inner sidewall surface of the horizontal flume (see Fig. 2) is also measured by using one of the video cameras installed above the generated Mach waves to cross-check the Froude number of the incident inundation flow evaluated by $F_{r i}=u_{i} / \sqrt{ } g h_{i}$, where $u_{i}$ is the moving velocity $\mathrm{d} x_{s} / \mathrm{d} t$ of the surge front, $g$ the gravitational acceleration and $h_{i}$ the maximum incident inundation depth evaluated by analyzing the above-mentioned measured data.

\section{Analysis Method}

Experiment on the density of the inundation water. Inundation flow goes down the slide slope, takes in the soil spread in the horizontal flume, runs up the short mild upslope at the downstream end of the horizontal flume and then jumps out into the air (see Fig. 2). Figure 3 shows snapshots (video images) of the inundation flow with a large amount of sediment, which were taken in the early experiments. After jumping out into the air, most inundation water with sediment is caught with the measuring cylinders which have $4 \mathrm{~cm}$ to $5.4 \mathrm{~cm}$ in diameter depending on the experimental cases and are evenly arranged in grid patterns to measure the horizontal spatial distribution of the volume and weight of the inundation water caught, which is a reflection of the vertical spatial distribution of sediment in the inundation flow. Weighed each measuring cylinder beforehand and after the inundation water jumped into, the density of the inundation water and its horizontal spatial distribution can be evaluated because of that the volume of the inundation water caught in each measuring cylinder can be read from the scale written to the circumference of each one.

The Froude number $F_{r i}$ and the velocity $u_{i}$ of the incident inundation flow are evaluated by the following three methods: 
- First method using the angle $\theta_{w}$ of the Mach wave caused by the slender prism and the maximum incident inundation depth evaluated by analyzing the data measured by using the video cameras arranged in the upper and side parts of the central area of the horizontal flume.

- Second method using the angle $\theta_{C}$ of the Mach wave caused by the point gauge and the maximum incident inundation depth evaluated by analyzing the data measured by using the video cameras arranged in the upper and side parts of the central area of the horizontal flume.

- Third method using the moving velocity of the surge front $(\cong$ incident inundation flow velocity is assumed) and the maximum incident inundation depth evaluated by analyzing the data measured by using the video cameras arranged in the upper and side parts of the central area of the horizontal flume.

The Shields number of the incident inundation flow for the case $h_{T}=6 \mathrm{~cm}$ is evaluated to grasp its rough value by using the resistance law for the steady flow in a wide rectangular open channel with a rough bottom surface, adopting the mean velocity of the moving velocities of points on the surge front surface at $0.5,1.0$ and $1.5 \mathrm{~cm}$ above the bottom surfaces of the horizontal flume and the short mild upslope measured by the two ultrasonic wave gauges as the incident inundation flow velocity, the mean depth of the maximum inundation depths measured by the ultrasonic wave gauges (depths at the arrow positions in Fig. 5 shown later) as the incident inundation depth $h_{i}$, 1.65 as the underwater specific gravity of soil, the median diameter $d_{50}$ as the representative diameter of soil and $3 \times d_{50}$ as the equivalent sand roughness (Ashida 1959).

Experiment on the run-up and sediment deposit. Inundation flow taken in the soil spread in the horizontal flume runs up and down the long mild upslope following the short mild upslope at the downstream end of the horizontal flume (see Fig. 2). Examples of the state of the sediment deposit and the run-up of the inundation flow on the long mild upslope are shown in Fig. 4. The long mild upslope area after finishing the run-up and down is divided into two parts. One is the tongue-shaped sedimentation area. The other is its downstream (higher) area where the upslope floor is just a little soiled with the sediment. The maximum length of the tongue-shaped sedimentation area is defined as the tsunami sediment deposit distance $L_{R S}$, and the sediment deposit thickness at each point of grid $(5 \mathrm{~cm}$ interval in the flow direction, $3.75 \mathrm{~cm}$ interval in the crossing direction) is measured by a point gauge.

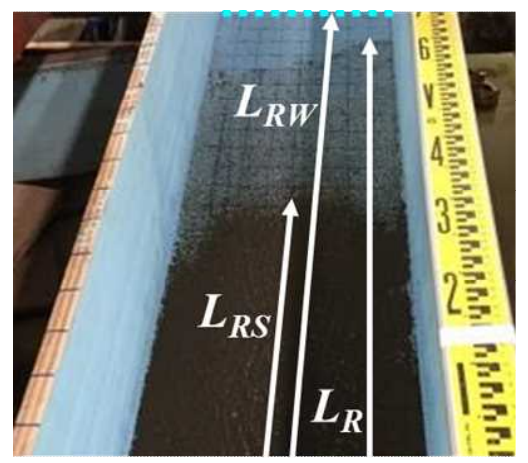

Figure 4. Examples of the state of the sediment deposit and the run-up of the inundation flow on the long mild upslope.

\section{Experimental Conditions}

The experimental conditions are summarized in Table 1 , where $h_{U}$ is the stored water depth in the water tank, $L_{S}$ the initial length of the spread soil area, $h_{S}$ the height of the short mild upslope end from the ground level, $L_{G}$ and $L_{V}$ the horizontal and vertical distances from the short mild upslope end to the upstream end of the measuring cylinders inclined at $S_{4}$ on the upstream side respectively, $h_{T}$ the initial thickness of the spread soil layer which is changed to adjust the density $\rho$ of inundation water (see Fig. 2), $M_{S D}$ the mass of the spread soil in the horizontal flume in the experiment on the density of the inundation water, $M_{S R}$ the mass of that in the experiment on the run-up and sediment deposit, U.C. and C.C. abbreviations of the uniformity and curvature coefficients respectively. In each experimental case, the soil cooled down naturally after drying by the drying oven is spread in the horizontal flume without taking any special measures of compaction and others. One run is performed under each experimental condition. 
Table 2. Experimental results (numerical value in the brackets is the arithmetic mean one for each measuring cylinder).

\begin{tabular}{|c|c|c|c|c|c|c|c|c|c|}
\hline \multirow[b]{2}{*}{ Case } & \multirow[b]{2}{*}{$\begin{array}{c}h_{T} \\
(\mathrm{~cm})\end{array}$} & \multirow[b]{2}{*}{$\rho\left(\mathrm{g} / \mathrm{cm}^{3}\right)$} & \multirow[b]{2}{*}{$L_{R} / L_{R W}$} & \multirow{2}{*}{$\begin{array}{l}L_{R S} \\
(\mathrm{~cm})\end{array}$} & \multirow{2}{*}{$\begin{array}{c}Z \\
(\mathrm{~cm})\end{array}$} & \multicolumn{3}{|c|}{$F_{r i}$} & \multirow{2}{*}{$\begin{array}{c}\text { Shields } \\
\text { num. }\end{array}$} \\
\hline & & & & & & $\begin{array}{c}\text { Mach } \\
\text { angle } \theta_{w}\end{array}$ & $\begin{array}{c}\text { Mach } \\
\text { angle } \theta_{C}\end{array}$ & $\begin{array}{l}\text { Surge } \\
\text { front }\end{array}$ & \\
\hline $1-1$ & 6 & $1.206(1.194)$ & - & - & - & - & - & 6.29 & - \\
\hline $2-1$ & 2 & $1.135(1.118)$ & $116 / 186$ & 63 & 0.36 & - & - & - & - \\
\hline $2-2$ & 6 & $1.092(1.077)$ & $117 / 186$ & 81 & 0.53 & - & - & 4.86 & - \\
\hline $2-3$ & 2 & $1.134(1.119)$ & 108/186 & 71 & 0.17 & - & - & - & - \\
\hline $2-4$ & 6 & $1.102(1.094)$ & $101 / 186$ & 72 & 0.15 & - & - & 4.81 & - \\
\hline $2-5$ & 2 & $1.125(1.101)$ & $116 / 186$ & 72 & 0.31 & - & - & 4.81 & - \\
\hline $2-6$ & 6 & $1.136(1.120)$ & 95/186 & 57 & 0.28 & - & - & 4.26 & - \\
\hline $2-7$ & 2 & $1.128(1.104)$ & $128 / 186$ & 80 & 0.15 & - & - & 4.43 & - \\
\hline $2-8$ & 6 & $1.158(1.129)$ & $111 / 186$ & 80 & 0.26 & - & - & 4.81 & - \\
\hline $3-1$ & 0.5 & $1.031(1.029)$ & $126 / 175$ & 102 & 0.14 & 3.52 & 4.28 & 3.82 & - \\
\hline $3-2$ & 1 & $1.062(1.035)$ & $112 / 175$ & 94 & 0.21 & 2.78 & 3.36 & 3.62 & - \\
\hline $3-3$ & 2 & $1.091(1.051)$ & $104 / 175$ & 92 & 0.22 & 3.89 & 3.58 & 4.55 & - \\
\hline $3-4$ & 6 & $1.155(1.094)$ & $100 / 175$ & 90 & 0.26 & 3.59 & 4.44 & 4.23 & 7.87 \\
\hline $3-5$ & 6 & $1.144(1.100)$ & - & - & - & 4.37 & 4.62 & 4.10 & 13.37 \\
\hline $4-1$ & 0.5 & $1.089(1.071)$ & $121 / 186.5$ & 82 & 0.23 & 2.34 & 3.12 & 2.28 & - \\
\hline $4-2$ & 1 & $1.082(1.063)$ & $120 / 186.5$ & 90 & 0.29 & 2.29 & 3.20 & 2.97 & - \\
\hline $4-3$ & 2 & $1.080(1.059)$ & $109 / 186.5$ & 75 & 0.22 & 2.11 & 3.12 & 2.76 & - \\
\hline $4-4$ & 6 & $1.084(1.051)$ & $95 / 186.5$ & 76 & 0.29 & 2.28 & 2.58 & 2.67 & 2.79 \\
\hline $4-5$ & 6 & $1.072(1.046)$ & - & - & - & 2.79 & 2.66 & 2.62 & - \\
\hline $4-6$ & 6 & $1.085(1.052)$ & - & - & - & 2.92 & 2.93 & 2.89 & - \\
\hline $4-7$ & 6 & - & $73 / 120$ & 24 & 0.12 & 2.29 & 2.52 & 2.09 & 1.63 \\
\hline $4-8$ & 6 & - & $85 / 171$ & 56 & 0.24 & 2.52 & 2.92 & 2.52 & 2.57 \\
\hline $4-9$ & 6 & - & - & 122 & 0.43 & 2.75 & 3.91 & 2.64 & 3.12 \\
\hline
\end{tabular}
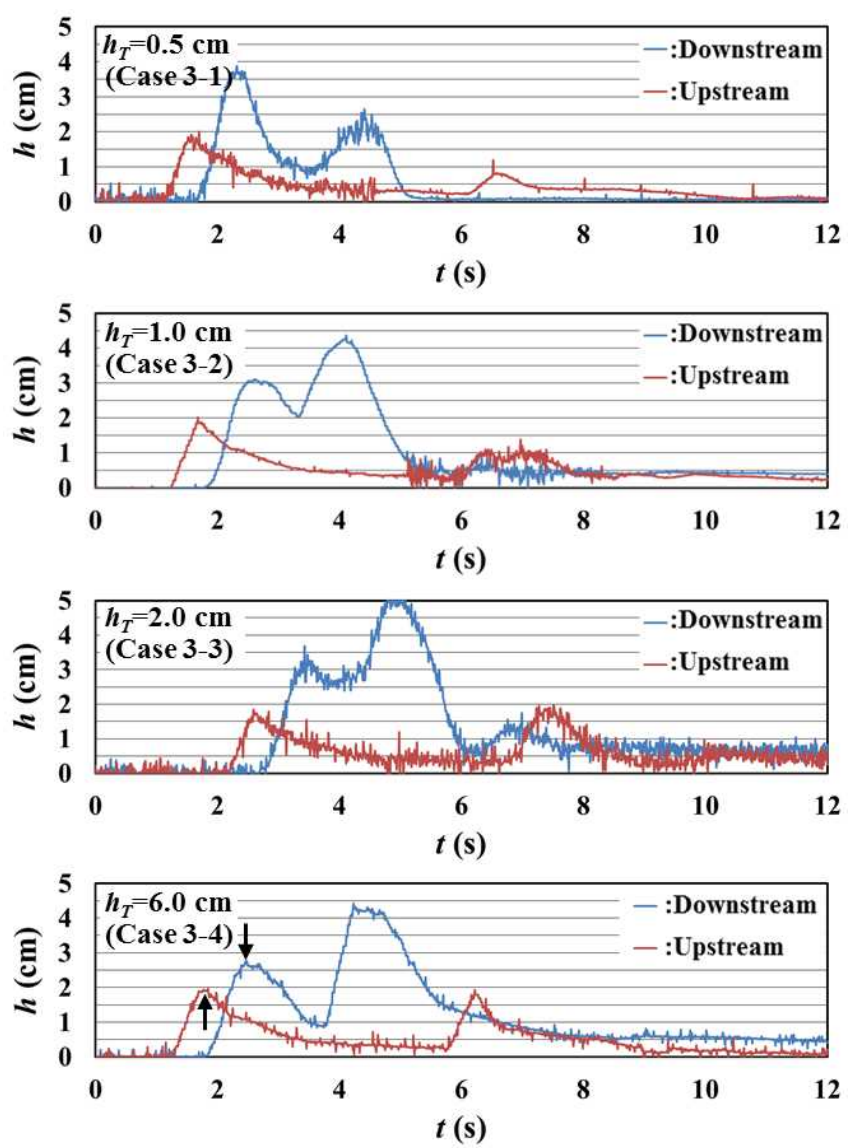

Figure 5. Examples of the time histories of the inundation depths $h$ at the upstream and downstream ends of the initially spread soil area in the horizontal flume. 


\section{RESULTS AND DISCUSSION}

Table 2 shows the summary of the experimental results, where the numerical value in the brackets is the arithmetic mean (= the horizontal spatial mean) value of the density $\rho$ evaluated for each measuring cylinder, and the result of Case 1-1 is the mean value in four runs exceptionally. From the table, it is understood that the arithmetic mean value of the density is always smaller than the value of the mean density evaluated from the total amount of the inundation water with sediment caught by the measuring cylinders. This tendency means that the repeatability of the experiment is high and the density evaluated from the measuring cylinder having more inundation water is higher than that having less inundation water. The Froude numbers in the experiments are greater than 2. From the viewpoint of the Froude number, it could be also judged that the generated inundation flow is different from a real tsunami inundation flow (Matsutomi 2011).

Figure 5 shows examples of the time histories of the inundation depths $h$ at the upstream and downstream ends of the initially spread soil area in the horizontal flume (see Fig. 2). The time $t=0$ for each experimental case is arbitrarily determined. The mean depth of the maximum incident inundation depths at the arrow positions in the figure is adopted as the inundation depth in the resistance law to evaluate the Shields number (see Table 2). From the figure, it is understood that the inundation depth at the downstream end $(h=2.7 \mathrm{~cm}$ to $3.6 \mathrm{~cm})$ is greater than that at the upstream end $(h=1.7 \mathrm{~cm}$ to $1.9 \mathrm{~cm})$ because of taking the soil into the inundation flow and decreases as the initial thickness $h_{T}$ of the spread soil layer in the horizontal flume increases. The reason of the decreasing inundation depth at the downstream end is considered that the inundation flow takes in more soil, spends more energy on the soil movement, loses more energy and moreover a reflection effect from the mild short upslope becomes smaller as the initial thickness of the spread soil layer increases.

Figure 6 shows the relationship between the Froude number $F_{r i}$ of the incident inundation flow and the density $\rho$ of the inundation water in the case of $h_{T}=6 \mathrm{~cm}$ that the bottom surface of the horizontal flume is not exposed, where the solid line is an upper envelope curve for the experimental data expressed by Eq. 1. From the figure, it is understood that the density $\rho$ becomes high, as the Froude number $F_{r i}$ increases, and the density $\rho$ depends on the sediment grain size $d_{50}$.

$$
\rho=0.056 F_{r i}^{0.7}+1
$$

Figure 7 shows the relationship between the density $\rho$ and the ratio $L_{R} / L_{R W}$ of the run-up distance of the inundation flow with sediment to that without sediment, where the solid line is an approximation curve for the experimental data expressed by Eq. 2. From the figure, it is understood that the run-up distance of the inundation flow with sediment decreases exponentially, as the density $\rho$ becomes high, and also the density $\rho$ becomes high as the initial thickness $h_{T}$ of the spread soil layer increases. As the density $\rho$ in the rapid decrease region of the run-up distance is very realistic, the rapid decrease becomes deeply involved in the historical tsunami scale evaluated from the tsunami sediment deposit distance.

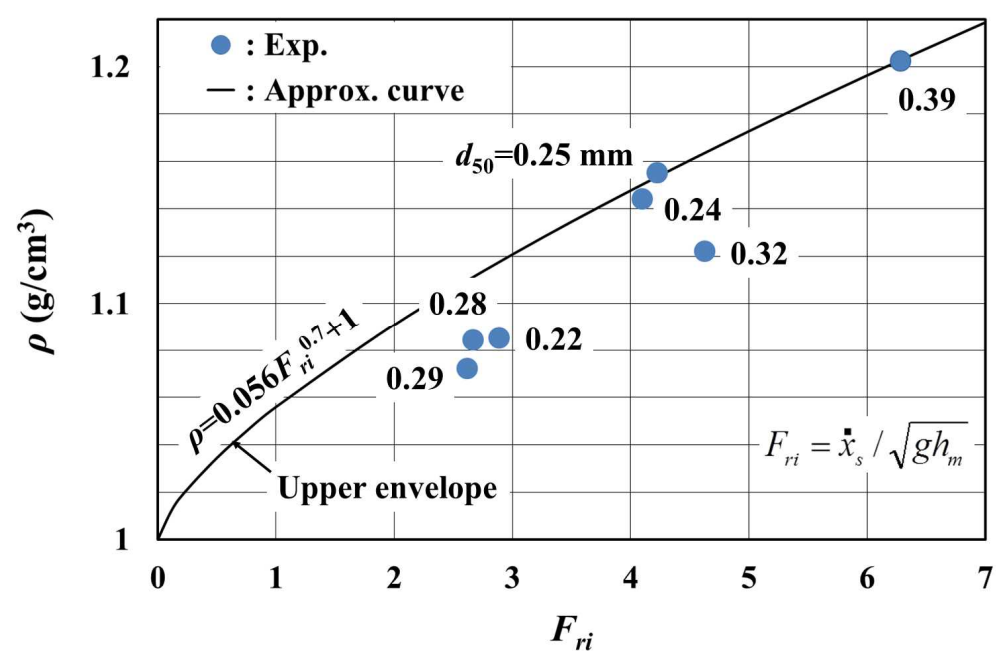

Figure 6. Relationship between the Froude number $F_{r i}$ of the incident inundation flow and the density $\rho$ of the inundation water with sediment in the case of $h_{T}=6 \mathrm{~cm}$ only. 


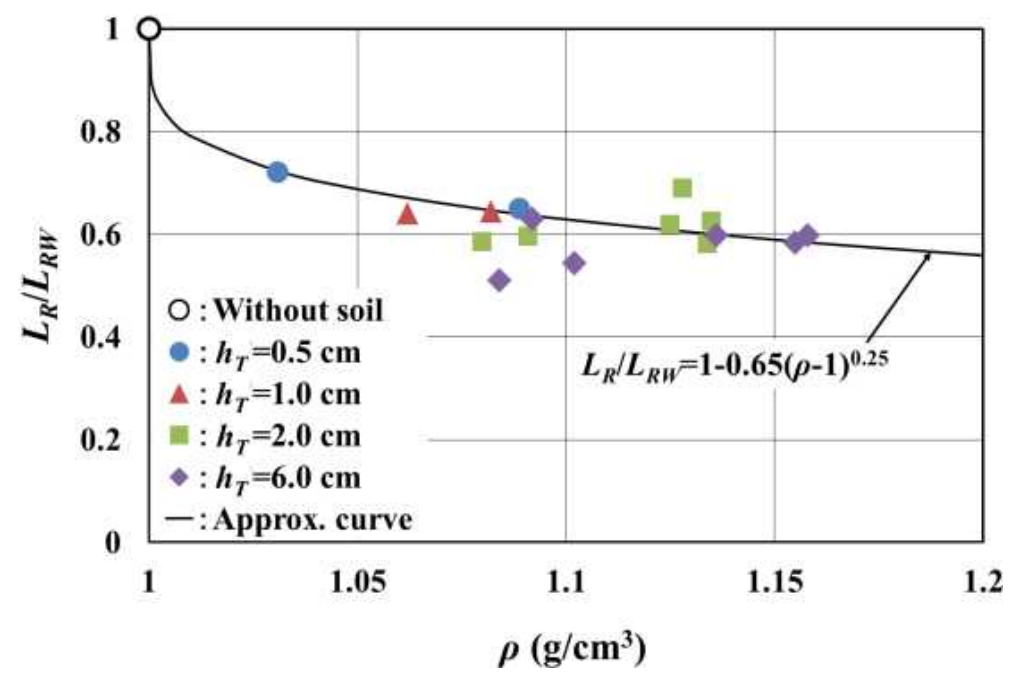

Figure 7. Relationship between the density $\rho$ of the inundation water and the ratio $L_{R} / L_{R W}$ of the run-up distance of the inundation flow with sediment to that without sediment.

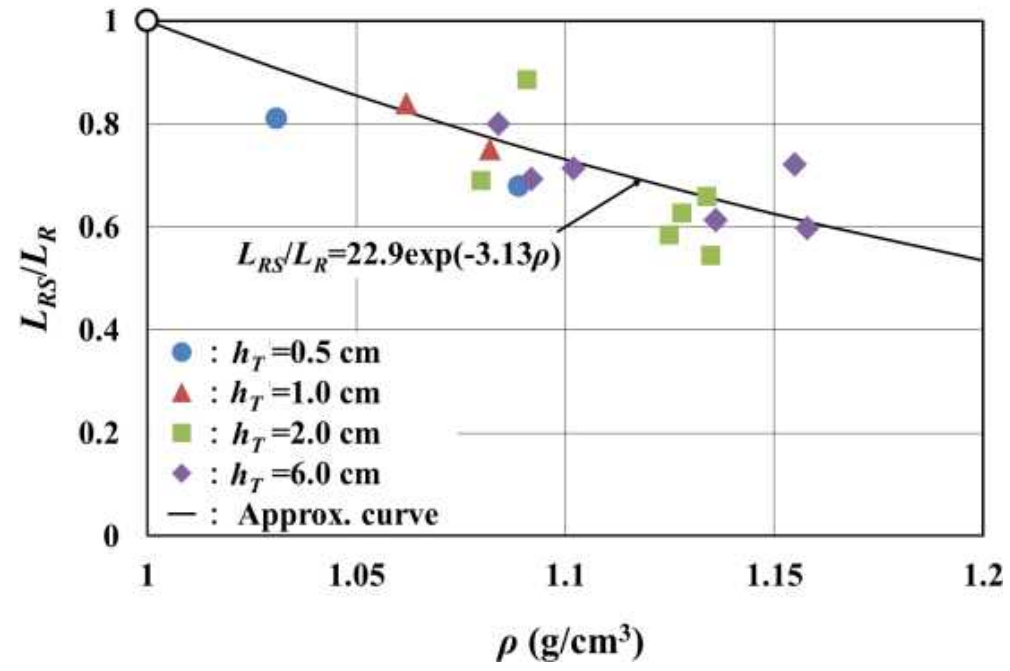

Figure 8. Relationship between the density $\rho$ of the inundation water with sediment and the ratio $L_{R S} / L_{R}$ of the sediment deposit distance to the run-up distance.

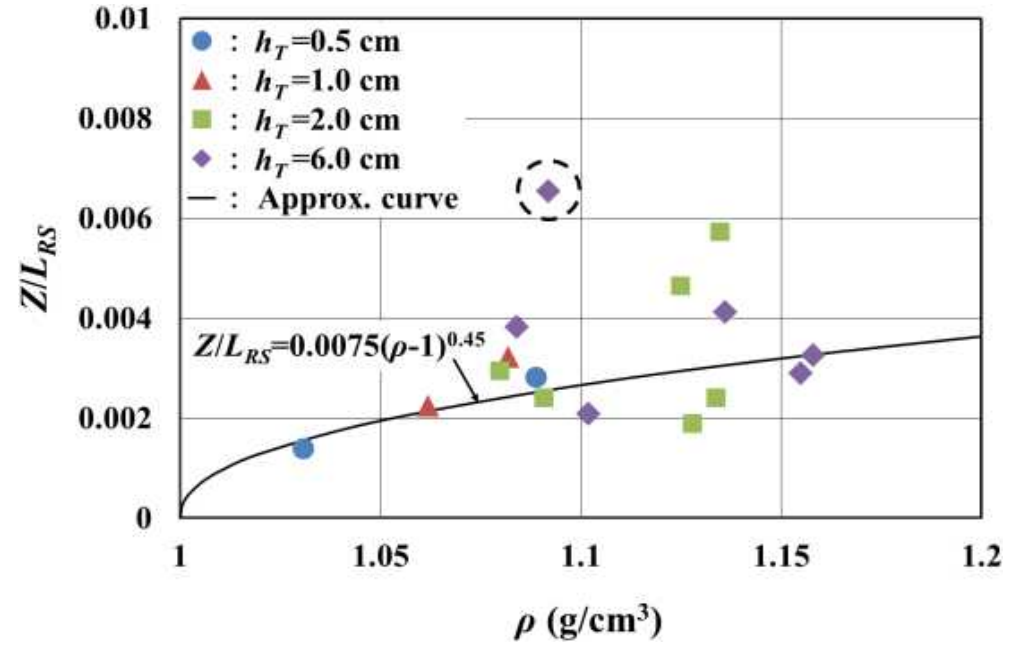

Figure 9. Relationship between the density $\rho$ of the inundation water and the ratio $Z / L_{R S}$ of the mean sediment deposit thickness to the sediment deposit distance. 


$$
\frac{L_{R}}{L_{R W}}=1-0.65(\rho-1)^{0.25}
$$

Figure 8 shows the relationship between the density $\rho$ and the ratio $L_{R S} / L_{R}$ of the sediment deposit distance to the run-up distance, where the solid line is an approximation curve for the experimental data expressed by Eq. 3. From the figure, it is understood that the ratio of the sediment deposit distance to the run-up distance decreases monotonically, as the density $\rho$ becomes high.

$$
\frac{L_{R S}}{L_{R}}=22.9 \exp (-3.13 \rho)
$$

Figure 9 shows the relationship between the density $\rho$ and the ratio $Z / L_{R S}$ of the mean sediment deposit thickness to the sediment deposit distance, where the solid line is an approximation curve for the experimental data expressed by Eq. 4. From the figure, it is understood that the ratio of the mean sediment deposit thickness to the sediment deposit distance increases with a tendency of convex upward, as the density $\rho$ becomes high.

$$
\frac{Z}{L_{R S}}=0.0075(\rho-1)^{0.45}
$$

\section{MAIN RESULTS}

Although the authors worry about the experimental method, small amount of experimental data and scale effect, main results obtained by this study are that:

1. The density $\rho$ (or the specific gravity $\rho / \rho_{w}$ ) of the inundation flow depends on the Froude number $F_{r i}$ of the incident inundation flow and the sediment grain size $d_{50}$ (Fig. 6).

2. The ratios $L_{R} / L_{R W}$ of the run-up distance of the inundation flow with sediment to that without sediment (Fig. 7), $L_{R S} / L_{R}$ of the sediment deposit distance to the run-up distance of the inundation flow with sediment (Fig. 8), $Z / L_{R S}$ of the mean sediment deposit thickness to the sediment deposit distance (Fig. 9) depend on the density $\rho$.

3. Four empirical formulas for the above dependencies are proposed, which are expressed by Eqs. 1 to 4 respectively.

\section{ACKNOWLEDGMENTS}

This work was supported by the Grant-in-Aid for Scientific Research from the Japan Society for the Promotion of Science (JSPS) and the Japanese Institute of Fisheries Infrastructure and Communities (JIFIC).

\section{REFERENCES}

Architectural Institute of Japan (AIJ). 2015. Chapter 10: Tsunami loads, Recommendations for loads on buildings, 577-579. (in Japanese)

Ashida, K. 1959. Design method for river channel, - on the roughness of river (4)-, Civil engineering journal, 1, 7, 8-11. (in Japanese)

FEMA. 2012. Guidelines for design of structures for vertical evacuation, FEMA P 646.

Matsutomi, H., K. Okamoto and K. Harada. 2011. Inundation flow velocity of tsunami on land and its practical use, Coastal Engineering, 32, Paper \#: currents.5.

Matsutomi, H., F. Konno, K. Atomura, K. Kondo, T. Kamataki and K. Watanabe. 2017. A quantitative experiment on the density of tsunami inundation water and its influence on the tsunami run-up distance and deposit, Journal of JSCE, B2, 73, 2, 373-378. (in Japanese) 